\title{
Fetal alcohol spectrum disorders: is it something we should be more aware of?
}

\author{
${ }^{1}$ RA Mukherjee, ${ }^{2} \mathrm{~S}$ Hollins, ${ }^{3} \mathrm{~L}$ Curfs \\ ${ }^{1}$ Consultant Psychiatrist, Specialist FASD Behavioural Clinic, Surrey and Borders Partnership NHS Foundation Trust, Surrey, UK; \\ ${ }^{2}$ Professor, Division of Public Health Sciences and Education, St George's University of London, UK; ${ }^{3}$ Professor, Klinische Genetica, \\ Maastricht University Medical Centre, Netherlands
}

This review is based in part on Dr Mukherjee's lecture at the RCPE Mental Health Needs of Children and Young People Symposium held in Edinburgh on 29 September 201I.

KEYWORDS Fetal alcohol syndrome, fetal alcohol spectrum disorders, overview, diagnosis, risk, clinical presentation

DECLARATION OF INTERESTS The FASD clinic has received honoraria with respect to Dr Mukherjee's lectures at conferences and educational meetings related to FASD from various charities and an industrial sponsor including TACT, PFC, NOFAS UK, Jannsen Cilag, Flynn Pharma and Oak Group. He is medical advisor to FASAware UK, FASD Trust UK and NOFAS UK.

\author{
Correspondence to RAS Mukherjee \\ Surrey and Borders Partnership \\ NHS Foundation Trust \\ Brackets Resource Centre \\ I / 6-I I 8 Station Rd East, \\ Oxted, Surrey RH80QA, UK
}

tel. +44 (0) I 883383787 e-mail Raja.mukherjee@sabp.nhs.uk

\section{INTRODUCTION}

Fetal alcohol spectrum disorders (FASD) describes a range of conditions caused by exposure to alcohol by a developing fetus.' The range of disorders vary from the most recognised fetal alcohol syndrome (FAS), where physical signs are obvious, to problems with behaviour and the brain with no obvious external physical signs (alcohol related neurodevelopmental disorders [ARND]).,3 This selective review will give an overview of many of the clinically relevant areas of FASD, including diagnostic difficulties, epidemiology, risk, knowledge among the general public, cognitive profiles and secondary disabilities.

\section{BACKGROUND}

The damaging effects to the fetus of maternal alcohol consumption during pregnancy have been recognised and commented on since as long ago as the Ancient Greek philosophers. ${ }^{4}$ There are references in the Bible relating to the ill effects of alcohol in pregnant women: 'You will conceive and give birth to a son. Now then drink no wine or fermented spirit.... ${ }^{5}$ While it could be argued that these quotes are taken out of context as the actual pathology of the damage was not known in the past, they do represent a long historical recognition that the effects of alcohol on a developing fetus can be harmful.

Calhoun and Warren ${ }^{4}$ describe the modern history of FAS, beginning with a case series published by Paul Lemoine in 1967..$^{\circ}$ A French paediatrician and his midwifery colleagues reported on 127 cases of children who had all been exposed to alcohol prenatally, and their later difficulties. The study did not, however, set out the diagnostic features required to identify the condition. The article that led to a change in the recognition and definition of the condition was published in 1973 in The Lancet by Smith and Jones. They reported on children living on an American Indian reserve who all presented with consistent, common and recognisable features, which they called fetal alcohol syndrome. ${ }^{7}$ All of the children's mothers had consumed high levels of alcohol during pregnancy. Smith and Jones set out a series of criteria which formed the basis for the development of diagnostic criteria for FASD.

The publication of Smith and Jones' articles and an increasing recognition of the condition generated a great deal of interest in FAS. Case studies considering the presentation of behavioural difficulties, neurological damage and physical characteristics of the disorder were published. ${ }^{8}$ Further, it was becoming clearer that alcohol could affect the brain without resulting in the distortions of facial features attributed to FAS. This led to a debate as to whether the term fetal alcohol effect (FAE) was a more accurate representation of the condition. ${ }^{9}$ Insights were obtained from both human examination and animal studies. It was through animal studies that perhaps our greatest understanding about the effects of alcohol during pregnancy were achieved, both from a pathological point of view, but also in clarifying the teratogenicity of alcohol. By using multiple animal models, allowing controlled experiments not possible in humans for ethical reasons, it became possible to begin to identify pathological processes, confirm cognitive profiles and explore possible therapeutic interventions. ${ }^{10}$

The Institute of Medicine (IOM) defined a set of criteria in 1996 for classifying the disorder. It was also recognised that prenatal exposure to alcohol could present with a spectrum of difficulties that would vary among individuals. ${ }^{4}$ The term FASD came into wider use towards the end of the 1990s, superseding the term FAE. 


\section{DIAGNOSTIC ISSUES IN FAS AND FASD}

The diagnostic elements of FAS are made up of three facial features (short palpebral fissures, elongated and flattened philtrum and a thin upper lip vermillion), preand postnatal growth deficits (below the tenth percentile), neurocognitive deficits and a history of maternal alcohol consumption during pregnancy. It is only in the case of FAS that confirmation of alcohol consumption is not required for the diagnosis. ${ }^{1,2}$ Timing is also important for diagnosis. When a child is still very young, features such as brain damage or developmental delay may not be obvious, while even at birth there may be signs of the distinct facial features, growth problems and evidence of maternal alcohol exposure. However, without the central nervous system (CNS) deficits, which are not always obvious at birth, a diagnosis of FAS is not valid. Despite this, a possible diagnosis, in anticipation of potential cognitive findings as a child grows older, should be noted and followed up.

While there is general agreement over the diagnostic features of FAS, debate continues over specific criteria. The cut-off figure used for palpebral fissure length for example is different across several diagnostic frameworks., ${ }^{2,11}$ Table I summarises the similarities and differences between the four main diagnostic frameworks in current practice.

The main difference between the groups remains whether or not the cut-off for palpebral fissure length should be the tenth or the third percentile. In the UK, ninth and second percentiles are now more commonly used. The difficulty in reaching agreement relates to the sensitivity and specificity of this cut-off measurement. A sensitivity test will pick up more of the true positive cases, while a specificity test will rule out more of the incorrect cases. The best test is one that has both high sensitivity and high specificity. Unfortunately, in most cases one tends to be higher than the other, leading to the discrepancies between the different diagnostic groupings and uncertainty about the reliability, accuracy and usefulness of the tests. Astley for example compared two diagnostic groupings, finding discrepancies between the methods used and the subsequent results obtained." These discrepancies highlight the inherent need for local norms for diagnosis to be agreed and established. The Canadian Guidance, developed by the Canadian Advisory group on FASD, is increasingly used as the best overview of all current guidelines. ${ }^{12}$

\section{OVERLAPPING SYMPTOMS}

One of the other difficulties in diagnosing FAS and FASD is because many of the established symptoms of FAS and FASD tend to be characteristic rather than discriminating. A characteristic symptom is one that is commonly seen in the disorder, however it may also be found as the result of other disorders. Discriminating symptoms occur uniquely as the result of a specific disorder. As FASD cases present mainly, if not wholly, with characteristic symptoms, it is only by exclusion of other disorders through genetic testing and through confirmation of alcohol consumption, that a reliable diagnosis can be established. Unfortunately, the amount and quality of information necessary to conduct such a careful differential diagnosis is frequently missing. In his editorial, Goddlett noted the establishment of a collaborative initiative who are attempting to overcome many of these issues and to bring consistency in diagnosis and management to the field of FASD. ${ }^{13}$

There has been much speculation and debate about the relationship between FASD and primarily attention deficit hyperactivity disorder (ADHD), but also its links with autism. Various types of relationships have been suggested, from direct causality to separate but overlapping disorders ${ }^{14,15}$ but as yet agreement about them

TABLE I Summary of the four main diagnostic frameworks and associated criteria'

\begin{tabular}{|l|l|l|l|l|}
\hline & $\begin{array}{l}\text { Centre For Disease } \\
\text { Control }\end{array}$ & $\begin{array}{l}\text { Institute of } \\
\text { Medicine (revised) }\end{array}$ & $\begin{array}{l}\text { Canadian National } \\
\text { Advisory Committee } \\
\text { on FASD }\end{array}$ & $\begin{array}{l}\text { 4-Digit Diagnostic } \\
\text { Code }\end{array}$ \\
\hline Face & $\begin{array}{l}\text { Tenth percentile } \\
\text { PFL and rank 4/5 on lip } \\
\text { philtrum }\end{array}$ & $\begin{array}{l}\text { Tenth percentile PFL } \\
\text { and rank 4/5 on lip } \\
\text { philtrum }\end{array}$ & $\begin{array}{l}\text { Third percentile PFL } \\
\text { and rank 4/5 on lip } \\
\text { philtrum }\end{array}$ & $\begin{array}{l}\text { Third percentile PFL } \\
\text { and rank } 4 / 5 \text { on lip } \\
\text { philtrum }\end{array}$ \\
\hline Growth & $\begin{array}{l}\text { Pre/postnatal growth } \\
\text { below tenth percentile }\end{array}$ & $\begin{array}{l}\text { Pre/postnatal growth } \\
\text { below tenth percentile }\end{array}$ & $\begin{array}{l}\text { Pre/postnatal growth } \\
\text { below tenth percentile }\end{array}$ & $\begin{array}{l}\text { Pre/postnatal growth } \\
\text { below tenth percentile }\end{array}$ \\
\hline Neurological & $\begin{array}{l}\text { One out of several } \\
\text { brain parameters } \\
\text { including OFC <10\%, } \\
\text { CNS deficits }\end{array}$ & $\begin{array}{l}\text { One out of one brain } \\
\text { parameters including } \\
\text { OFC <10\%, CNS } \\
\text { deficits } \\
\text { Or abnormal structure }\end{array}$ & $\begin{array}{l}\text { 3+ soft and hard } \\
\text { neurological signs }\end{array}$ & $\begin{array}{l}\text { One out of several } \\
\text { brain parameters } \\
\text { including OFC }<3 \%, \\
\text { CNS deficits }\end{array}$ \\
\hline Alcohol & $\begin{array}{l}\text { Confirmed to be } \\
\text { excessive or unknown }\end{array}$ & $\begin{array}{l}\text { Confirmed or } \\
\text { unknown }\end{array}$ & $\begin{array}{l}\text { Confirmed or } \\
\text { unknown }\end{array}$ \\
\hline PFL= palpebral fissure length; OFC= orbitofrontal cortex; CNS= central nervous system & \\
\hline
\end{tabular}


remains elusive. We recently reported higher rates of autism were being found in people with FASD diagnoses. ${ }^{16}$ We believe the association between the two appears to be more than what might be attributed to chance. Therefore we believe, as others have for similar conditions, ${ }^{17}$ that more research is needed in order to establish the relationship between the phenomenology and the underlying neurological pathology. ${ }^{16}$

\section{EPIDEMIOLOGY}

The original IOM criteria were used in various epidemiological studies of FAS and FASD but they were refined in 2006, ${ }^{2}$ leading to wide variations in the reported prevalence rates from those originally stated..$^{18,19}$ Other problems were found with other studies. An investigation by May et al. for example in Lazio, Italy, showed that the prevalence rates of the full spectrum of FASD was estimated at 35 people per $1,000 .^{20}$ Unfortunately, despite actively recruiting study participants (proactively identifying cases rather than passively waiting for them to be reported) in order to establish prevalence, the study group moved people between diagnostic groupings based on clinical review rather than strict adherence to the study design. This led to criticism of the study, most specifically in regards to the validity of the results. ${ }^{20}$

A later study by Petkovic and Barisic, using similar methodology as the May study, but without the same limitations and criticisms, showed similar findings in a population of school-aged children.' They actively recruited participants in two regions of Croatia (over I,200 people). This study showed an overall prevalence rate of FAS and partial FAS of $40.77 / 1,000 .^{21}$ However these studies have yet to be widely replicated by other groups. The suggestion from studies thus far is that the prevalence rate in the full population is higher than previously thought. Table 2 summarises studies that used the same methodology, however the actual rate in many parts of the world is still unclear. The results however continue to represent the best available estimates of prevalence.

In the UK there have been no actively recruited studies. This is unfortunate, as passive surveillance studies have been shown to have poor reliability due to the underreporting of the rates of prevalence. A recently published study completed a review of paediatric hospital episode statistics in the UK over a five-year period which showed a progressive increase in the rates, but ultimately they were much lower than expected. ${ }^{22}$ The true prevalence in the UK therefore still needs to be established.

\section{ALCOHOL CONSUMPTION AND THE LEVEL OF RISK}

Establishing the actual level of alcohol consumed during pregnancy in order to accurately diagnose the disorder is challenging but necessary. Despite attempts to improve awareness of the need for this information, problems persist partly because alcohol exposure is not often recorded in the medical records of children or mothers. ${ }^{22}$ It has also been reported that the recall of alcohol consumption amounts is poor. ${ }^{23}$ Different ways of improving the recording of what women drink during pregnancy continue to be researched. Existing methods range from the use of specialist screening tools such as the T-ACE questionnaire or the Alcohol Disorders Identification Test (Audit-C) to the use of specific biomarkers. ${ }^{1,14}$ The screening tools raise concerns because they rely on honest reporting. To circumvent these concerns, a search for biomarkers such as free fatty ethyl esters in meconium can be done. ${ }^{1,24,25}$ Unfortunately, these biomarkers only pick up second and third trimester alcohol consumption. There are also ethical considerations around the use of biomarkers in the absence of informed consent, particularly since the level of risk has not been established. ${ }^{26}$ The implications of this on the wider 'drinking during pregnancy' debate must also be considered.

Another challenge to collecting data on individual alcohol consumption during pregnancy is a lack of a clear definition of what is considered to be a 'safe' amount of alcohol. ${ }^{27,28}$ Studies have shown dose-response relationships between levels of alcohol consumption and harm: higher levels of alcohol exposure were found to cause the most obvious neurodevelopmental problems; ${ }^{27,29-31}$ lower levels of alcohol exposure are more difficult to assess, with some studies reporting no clear differences compared to a non-exposed group, ${ }^{29,30,32-38}$ while others continue to suggest possible effects of even low exposure levels. ${ }^{31,35,39-41}$ As such, the levels of individual risk remain uncertain.

TABLE 2 Estimated prevalence rates per thousand population from different studies ${ }^{18-2}$

\begin{tabular}{|l|l|l|l|}
\hline & Fetal Alcohol Syndrome & $\begin{array}{l}\text { Partial Fetal Alcohol } \\
\text { Syndrome }\end{array}$ & $\begin{array}{l}\text { Fetal Alcohol Spectrum } \\
\text { Disorders }\end{array}$ \\
\hline $\begin{array}{l}\text { May et al., South Africa } \\
(2007)^{18,19}\end{array}$ & $51.3-67.2$ & $16.8-22.0$ & $68.0-89.2$ \\
\hline May et al., Italy (2006) ${ }^{20}$ & $3.7-7.4$ & $15.7-31.3$ & $20.3-40.5$ \\
\hline $\begin{array}{l}\text { Petrovic et al., Croatia } \\
(2010)^{21}\end{array}$ & 6.4 & 34.3 & 40.77 \\
\hline
\end{tabular}


Perhaps unsurprisingly, given the difficulties stated above, the advice about drinking alcohol during pregnancy currently differs from country to country. ${ }^{42}$ In the UK for example, women are advised to avoid alcohol consumption if possible and, if they do drink alcohol, to consume no more than one to two drinks in a single sitting. However, the definition of how much alcohol constitutes one to two drinks is often confusing and unclear. Combined with the public's limited understanding of the scientific conclusions about the risks of drinking alcohol during pregnancy, this creates a dangerous situation. ${ }^{28}$

\section{AWARENESS AND UNDERSTANDING OF FASD IN THE GENERAL POPULATION}

Internationally and more specifically in the UK, conflicting evidence regarding the effects of alcohol during pregnancy has seemingly led to inconsistent understanding of FASD in both professionals and the public. ${ }^{43-50}$ This has implications for the management and the prevention of the disorder. The development of a consistent public health strategy remains a challenge, particularly when the condition is one that, unlike many others, can be entirely prevented simply by not consuming alcohol while pregnant. As such, it has been argued that FASD constitutes a public health disorder that requires directed prevention strategies. ${ }^{24,51,52}$

The lack of consistent guidelines and the subsequent confusion over health strategy means that providing support for individuals and families can be challenging. This increases the health burden and stress faced by those with FASD and their families. ${ }^{53-58}$ The publicly funded health and social care system in the UK is accessible by all and therefore may well offer better support to those with FASD and their families compared to countries in which access is more limited, although budget limitations may well mean the opposite is also true. The situation is currently unclear and requires clarification.

\section{EVIDENCE FROM ANIMAL STUDIES ON THE EFFECTS OF ALCOHOL}

Part of the difficulty of finding evidence that supports the labelling of alcohol as a teratogen relates to the ethical and practical aspects of conducting this research. Ethically, it is not possible to conduct controlled human experiments into the risks of alcohol during pregnancy. Population-based studies are inherently biased by confounding factors. For example, alcohol consumption by the mother is known to cause prematurity, ${ }^{59}$ yet prematurity itself is also known to cause cognitive deficits regardless of what may have caused it. ${ }^{60}$ Further, much of the population-based work is subject to bias, especially in terms of recall of alcohol consumption. ${ }^{61}$ To overcome this and statistically correct for these confounding factors, large numbers of research participants are required.
Alternative methods for researching this subject have been suggested (such as the use of natural experiments) but have yet to be widely implemented. ${ }^{62}$

Instead, animal studies have formed the basis for providing the basic pathology of FASD. Hannigan summarised the research undertaken in the years prior to his review in 1996. ${ }^{63} \mathrm{He}$ looked at the data collected using animal research, including evidence about dose-response rates, timing of exposure and risk, neuro-anatomical and neuro-behavioural dysfunctions and offered an insight into potential future treatments. Despite the availability of this evidence, the report concluded by suggesting that much more work was still needed.

Sulik's study helped identify the dose-dependent effect of alcohol on the development of facial features and clarified how the timing of alcohol exposure affects subsequent fetal development by identifying a risk period during weeks three to four of gestation. She also considered factors that may alter alcohol teratogenesis between individuals. ${ }^{64} \mathrm{Her}$ research has implications for humans in that, in the UK at least, women are drinking more than in the past and the patterns of this alcohol consumption both in terms of who is consuming alcohol and where it is consumed have changed. ${ }^{65}$ More women are consuming alcohol at levels that are associated with the levels of risk identified in the animal studies. ${ }^{66}$ The timing of pregnancy recognition is therefore crucial in helping women to refrain from alcohol consumption during the earliest period in the pregnancy when facial features of the fetus are most susceptible to damage. Many women will consume alcohol until pregnancy is detected, usually between the first and second missed period. Once pregnancy is confirmed, however, around $67 \%$ of women in the UK will significantly reduce or stop drinking. ${ }^{23}$ As a result, it seems likely that for some fetuses, damage to the facial features may occur, but later development may continue, unaffected by alcohol, leading to the subsequent unhindered development of the brain and body. This in itself has implications for relying solely on facial features for the diagnosis of FAS and confirms the importance of the cognitive features in the diagnosis. It is clear from the literature on animal studies that the risks of alcohol consumption during pregnancy exist during all trimesters, not just the first. ${ }^{63,64}$ Ongoing brain development in the second and third trimesters means that public health advice regarding alcohol consumption must also cover these trimesters.

While many have extrapolated the results of the animal studies to the human population, some authors have questioned the methods of animal research and the applicability of the conclusions of the results to humans. Abel argues for example that in some of the animal experiments that refer to "low blood alcohol concentrations', rather than representing low levels of alcohol 
in the bloodstream, this actually describes concentrations that would correspond to high levels of alcohol in a human. He points out that the methods of alcohol delivery, such as putting animals onto liquid alcohol diets, do not reflect human consumption patterns, making interpretation difficult. A six gram dose of alcohol in a rat for example equates to 27 drinks per day in an average human (where a US drink equated to I.5 UK units). ${ }^{32}$ In their paper, Leichter and Lee confirm that the method of alcohol delivery in animal studies represents a confounding factor in their interpretation. ${ }^{67}$

Despite these issues, animal studies remain the only way to ethically study the effects of alcohol on fetuses and confirm its teratogenicity. By showing consistent findings in multiple animal models it is possible to make comparisons to the human findings from populationbased research. Cudd describes the strengths and weaknesses of different models of exploration, concluding that substantial progress in the field will require the judicious use of multiple scientific approaches using different animal systems. ${ }^{68}$

\section{COGNITIVE PROFILE OF PEOPLE WITH FASD}

Population-based studies and studies of affected individuals have corroborated many of the findings from the animal studies. Jacobson and Jacobson summarised some of the early findings (Table 3). ${ }^{69}$ Rasmussen carried out a systematic review of executive function (the set of cognitive abilities that control and regulate other abilities and behaviours) and working memory ${ }^{70}$ and confirmed these two areas of deficit found in experimental studies contributed to the difficulties in function seen in affected individuals. Rasmussen's review complimented much of the work of Matteson and colleagues, who looked at IQ and its relationship to facial features ${ }^{71}$ as well as how executive functioning in this group was affected by alcohol. ${ }^{72}$ They contributed much to the understanding of

TABLE 3 Summary of main cognitive deficits seen in people with fetal alcohol spectrum disorder

- Intellectual disabilities and reduced IQ

- Executive functioning difficulties

- Hyperactivity

- Inattention

- Social communication problems

- Integration of information problems

- Concrete thinking

- Difficulty with abstract concepts

- Cognitive flexibility issues

- Working memory problems

- Processing speed deficits

- Spatial awareness problems

- Mathematical problems

- Cerebellar problems

- Hemispheric linkage problems how the condition presents. Others, such as Burden and colleagues, have shown how attention and pressure of time to complete a task can affect those with FASD by studying working memory and processing speed. ${ }^{73,74}$ Sampson and colleagues have further highlighted that pressure and time affect the accuracy of an individual's results on cognitive tests. Roebuck et al. looked at the importance of the corpus callosum damage caused by maternal alcohol consumption and the impact that this has on cognitive presentation and the ability of those affected to link information between cerebral hemispheres. ${ }^{75}$ All of these findings have implications for the management of FASD, by establishing that performance can be improved by reducing external expectations and time pressures on those affected. ${ }^{76}$

Increased understanding of the condition and the correlation of psychometric findings with neuro-imaging studies has led to a more refined profile. ${ }^{77}$ Using data from two sites of a multi-site FASD international project, Matteson et al. found that executive functioning and spatial processing were especially sensitive to prenatal alcohol exposure. ${ }^{78}$ The remaining challenge is to identify how these cognitive profiles can help to integrate and establish management strategies on the basis of individual diagnostic profiles. Kodituwakku for example, has argued that in reality, a broader framework of understanding and subsequent intervention is needed in order to bring together the cognitive profiles to allow better management of this condition. ${ }^{79}$

\section{SECONDARY DISABILITIES}

As a child grows into an adult, the secondary disabilities associated with FASD are increasingly recognised. Secondary disabilities are defined as those caused by inadequate recognition and support management of the primary disability. Streissguth et al. published a list of secondary disabilities from a long-term cohort study where participants were followed up for over 30 years. ${ }^{80,81}$ These deficits are summarised in Table 4. Steinhaussen and Spohr have also conducted a long-term follow-up study showing the difficulties that continue into adulthood. ${ }^{82}$ While support on an individual level has been shown to lead to a better overall outcome, a lack of that same support is known to lead to significant

TABLE 4 Common secondary disabilities seen if individuals are not recognised and supported

- Mental health issues

-All form of mental illness

- Increased suicide rates

- Crime and incarceration

- Sexual inappropriateness

- Substance abuse

- Educational difficulties 
difficulties. Mental health issues are the most frequently recognised of these disabilities: $90 \%$ of individuals affected by FASD suffer some form of mental illness. Famy first reported on the mental health issues in this group as far back as 1997 in a brief report to The Journal of the American Medical Association. ${ }^{83}$ Unfortunately, as the report was based on a very small number of participants, the findings were not widely accepted. The data, however, were corroborated in a study by Barr et al in 2006. In a larger series they showed high rates of mental illness. The larger sample also allowed statistical correction for confounding factors influencing the outcomes. ${ }^{84}$ In addition, it has been found that people with FASD who also suffer with mental illness have been associated with higher rates of suicide. ${ }^{85}$

Larger scale epidemiological studies have increasingly been used to look at the wider impact of prenatal alcohol exposure on both developmental and mental health presentation. Work conducted by Kelly et al. for example, showed that, in a sample of II,5I3 people, low levels of alcohol exposure had less of an impact on socioemotional or cognitive outcomes. They did however show a clear relationship between higher levels of alcohol exposure and cognitive deficits. ${ }^{30}$ This was in contrast to findings by Sayal et al. who found that girls aged nine were more likely to suffer mental health

\section{REFERENCES}

I BMA Board of Science. Fetal Alcohol Spectrum Disorders, a guide for healthcare practitioners [Internet]. London: BMA Publishing; 2007 [cited 2012 March 28]. Available from: http://www.bma.org.uk/ images/FetalAlcoholSpectrumDisorders_tcm4I-I58035.pdf

2 Hoyme HE, May PA, KalbergWO et al.A practical clinical approach to diagnosis of Fetal Alcohol Spectrum Disorders: clarification of the 1996 Institute of Medicine criteria. Pediatrics 2005; II5:39-47. http://dx.doi.org/I0.1542/peds.2005-0702

3 Mukherjee RA, Hollins S, Turk J. Fetal Alcohol Spectrum Disorder: an overview.J R Soc Med 2006;99:298-302.http://dx.doi.org// 0.1258/ jrsm.99.6.298

4 Calhoun F, Warren KR. Fetal Alcohol Syndrome: historical perspectives. Neurosci Biobehav Rev 2007; 31:I68-7I. http://dx.doi. org/I0.1016/j.neubiorev.2006.06.023

5 The Bible (New international version). Judges 13:7. Michigan: Biblica; 20I I.

6 Lemoine P, Harousseau $\mathrm{H}$, Borteryu JP et al. [The children of alcoholic parents: anomalies observed in 127 cases]. Quest Medicale 1968; 25:476-82.

7 Jones KL, Smith DW, Ulleland CN et al. Pattern of malformation in offspring of chronic alcoholic mothers. Lancet 1973; I:|267-7I. http://dx.doi.org/10.1016/S0I40-6736(73)9129I-9

8 Warren KR, Foudin LL. Alcohol-related birth defects: the past, present, and future. Alcohol Res Health 200I; 25: I53-8.

9 Clarren SK, Smith DW. The fetal alcohol syndrome. N Engl J Med 1978;298: I063-7.http://dx.doi.org/I0.I056/NEJMI 97805 I I 298I906

10 Chandrasena AN, Mukherjee RA, Turk J. Fetal Alcohol Spectrum Disorders: an overview of interventions for affected individuals. Child and Adolescent Mental Health 2009; 14:162-7. http://dx.doi. org/I0.IIII/j.I475-3588.2008.00504.x

I I Astley SJ. Comparison of the 4-Digit code and the Hoyme diagnostic guidelines for Fetal Alcohol Spectrum Disorders. Paediatrics 2006; I 18:1532-45. http://dx.doi.org/I0.1542/peds.2006-0577 problems even at maternal alcohol consumption levels of less than one UK unit a week (in a sample of 8,046 people). ${ }^{31}$ At present these contrasting findings leave almost as many questions as answers. More research will be required to clarify these issues.

\section{CONCLUSIONS}

Recognising and managing FASD is a challenge in the UK. Discrepancies in the scientific literature continue to raise questions about the condition, but there is general agreement that FASD will demand significant preventive, medical and social care resources in the future. Overall, better training on FASD and its impact is needed for all professionals working in the fields of health, social work, criminal justice and education. If the situation in the UK is to improve, with a decrease in the number of people with FASD achieved, the cause and impact of the condition must be clarified and widely and consistently communicated to professionals and the public. While some changes have already begun to happen, there is a great deal left to do.

Acknowledgements: Many thanks to Matt Commers, Maastricht University for comments on early drafts of this paper.

12 Chudley AE, Conry J, Cook JL et al. Fetal Alcohol Spectrum Disorder: Canadian guidelines for diagnosis. CMAJ 2005:I72:SIS21. http://dx.doi.org/10.1503/cmaj. 1040302

13 Goodlett CR. Fetal Alcohol Spectrum Disorders: new perspectives on diagnosis and intervention. Alcohol 2010; 44:579-82. http://dx. doi.org/10.1016/j.alcohol.2010.10.001

I4 Gray R, Mukherjee RA. A psychiatrists guide to Fetal Alcohol Spectrum Disorders in mothers who drank heavily during pregnancy. Advances in Mental Health and Intellectual Disabilities 2007; I:19-26.

15 Oesterheld JR, Wilson A. ADHD and FAS. J Am Acad Child Adolesc Psychiatry 1997; 36:1/63. http://dx.doi.org//0.1097/00004583199709000-00004

16 Mukherjee RA, Layton M, Yacoub E et al.Autism and autistic traits in people exposed to heavy prenatal alcohol: data from a clinical series of 21 individuals and a nested case control study. Advances in Mental Health and Intellectual Disabilities 20I I; 5:42-9. http:// dx.doi.org/10.5042/amhid.201 I.0015

17 McGough JJ, McCracken JT. Adult attention hyperactivity disorder: moving beyond DSM-IV. Am J Psychiatry 2006; 163:1673-5. http:// dx.doi.org/I0.II76/appi.ajp.163.10.1673

I8 May PA, Gossage JP, Kalberg WO et al. Prevalence and epidemiological characteristics of FASD from various research methods with an emphasis on recent in-school studies. Devl Disabil Res Rev 2009; I5:176-92. http://dx.doi.org/I0.1002/ddrr.68

19 May PA, Gossage JP, Marais AS et al. The epidemiology of Fetal Alcohol Syndrome and Partial FAS in a South African community. Drug Alcohol Depend 2007; 88:259-7I. http://dx.doi.org/I0.1016/j. drugalcdep.2006.I I.007

20 May PA, Fiorentino D, Phillip Gossage J et al. Epidemiology of FASD in a province in Italy: prevalence and characteristics of children in a random sample of schools. Alcohol Clin Exp Res 2006; 30:1562-75. http://dx.doi.org/I0.IIII/j.1530-0277.2006.00188.x 
21 Petkovic G, Barisic I. FAS prevalence in a sample of urban schoolchildren in Croatia. Reprod Toxicol 2010; 29:237-4I. http:// dx.doi.org/10.1016/j.reprotox.2009.11.006

22 Morleo M, Woolfall K, Dedman D et al. Under-reporting of Fetal Alcohol Spectrum Disorders: an analysis of hospital episode statistics. BMC Pediatr 20 I I; I I:I4.

23 Smith LA, Foxcroft D. Drinking in the UK: an exploration of trends [Internet]. York: Joseph Rowntree Foundation; 2009 [cited 2012 March 28]. Available from: http://www.jrf.org.uk/publications/ drinking-in-the-uk

24 Warren KR, Hewitt BG, Thomas JD. Fetal Alcohol Spectrum Disorders: research challenges and opportunities. Alcohol Research \& Health 2011; 34:4-14.

25 Hutson J. Meconium fatty acid ethyl esters and prediction of fetal alcohol effects. J FAS Int 2006; 4: I-3.

26 Mukherjee RA, Eastman N, Turk J et al. Fetal Alcohol Syndrome: law and ethics. Lancet 2007; 369: I |49-50. http://dx.doi.org/I0.1016/ SOI40-6736(07)60542-X

27 Henderson J, Gray R, Brocklehurst P. Systematic review of effects of low-moderate prenatal alcohol exposure on pregnancy outcome. BJOG 2007; II4:243-52. http://dx.doi.org/I0.I I II/j.I47I-0528.2006 0II63.x

28 Mukherjee RA, Hollins S, Abou-Saleh MT et al. Low level alcohol consumption and the fetus. BMJ 2005; 330:375-6. http://dx.doi. org/I0.II36/bmj.330.7488.375

29 Disney ER, lacono W, McGue M et al. Strengthening the case: prenatal alcohol exposure is associated with increased risk for conduct disorder. Pediatrics 2008; 122:el225-30. http://dx.doi. org/I0.1542/peds.2008-I380

30 Kelly YJ, Sacker A, Gray R et al. Light drinking during pregnancy: still no increased risk for socioemotional difficulties or cognitive deficits at 5 years of age? J Epidemiol Community Health 2012; 66:41-8. http://dx.doi.org/10.1 I36/jech.2009.103002

3I Sayal K, Heron J, Golding J et al. Prenatal alcohol exposure and gender differences in childhood mental health problems: a longitudinal population-based study. Pediatrics 2007; II9:e426-34. http://dx.doi.org/I0.1542/peds.2006-1840

32 Abel EL. Fetal Alcohol Syndrome: same old, same old. Addiction 2009;104:1274-5.http://dx.doi.org//0.1 I I I/j.1360-0443.2008.0248I.x

33 Alati R, MacLeod J, Hickman $M$ et al. Intrauterine exposure to alcohol and tobacco use and childhood $\mathrm{IQ}$ : findings from a parental-offspring comparison within the Avon Longitudinal Study of Parents and Children. Pediatr Res 2008; 64:659-66. http://dx.doi. org/I0.1203/PDR.0b0I3e3I8I87cc3 I

34 Henderson J, Kesmodel U, Gray R. Systematic review of the fetal effects of prenatal binge-drinking. J Epidemiol Community Health 2007; 6I:I069-73. http://dx.doi.org/I0.II36/jech.2006.0542 I3

35 Kaskutas LA, Graves K. Pre-pregnancy drinking: how drink size affects risk assessment. Addiction 2001; 96: I 199-209. http://dx.doi. org/I0.1046/j. I360-0443.200I.968II99I2.x

36 O'Leary CM, Nasser N, Kurinczuk IJ et al. Prenatal alcohol exposure and risk of birth defects. Pediatrics 2010; I26:e843-50. http://dx.doi.org/l0.1542/peds.2010-0256

37 D'Onoforio BM, Van Hulle CA, Waldman ID et al. Causal inferences regarding prenatal alcohol exposure and childhood externalising problems. Arch Gen Psychiatry 2007; 64:1296-304. http://dx.doi.org/I0.I00 I/archpsyc.64.I I.1296

38 Patra J, Bakker $\mathrm{R}$, Irving $\mathrm{H}$ et al. Dose-response relationship between alcohol consumption before and during pregnancy and risk of low birthweight preterm birth and small for gestational age (SGA): a systematic review and meta-analyses. BJOG 201I,

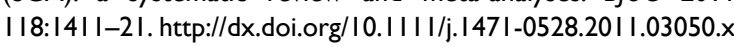

39 Chaudhuri JD. Effect of a single dose of ethanol on developing skeletal muscle of chick embryos. Alcohol 2004; 34:279-83. http:// dx.doi.org//0.10I6/j.alcohol.2004.07.012

40 leraci A, Herrera DG. Single alcohol exposure in early life damages hippocampal stem/progenitor cells and reduces adult neurogenesis. Neurobiol Dis 2007; 26:597-605. http://dx.doi.org/10.1016/j. nbd.2007.02.0I I
4I Ikonomidou C, Bittigau P, Ishimaru MJ et al. Ethanol-induced apoptotic neurodegeneration and Fetal Alcohol Syndrome. Science 2000;287: 1056-60.http://dx.doi.org/ I0.I I26/science.287.5455.1056

42 International Centre for Alcohol Policies. International guidelines on drinking in pregnancy [Internet]. Washington DC: International Centre for Alcohol Policies; 2009. Available from: http//www.icap. org/table/internationalguidelinesondrinkinginpregnancy 2009

43 Abel EL, Kruger M.What do physicians know and say about Fetal Alcohol Syndrome?: a survey of obstetricians, pediatricians and family medicine physicians. Alcohol Clin Exp Res 1998; 22:1951-4. http://dx.doi.org/I0.1 I I I/j.1530-0277.1998.tb05902.x

44 Gahagan S, Sharpe TT, Brimacombe $M$ et al. Pediatrician's knowledge, training and experience in the care of children with Fetal Alcohol Syndrome. Pediatrics 2006; II8:e657-68. http:// dx.doi.org/I0.1542/peds.2005-05I6

45 Haemmerlie FM, Merx CJ, Nelson SB. College vs junior high school students' knowledge of alcohol as a teratogen. Psychol Rep 1992; 71:809-10. http://dx.doi.org//0.2466/pr0.1992.71.3.809

46 Kesmodel U, Kesmodel PS. Drinking during pregnancy: attitudes and knowledge among pregnant Danish women, 1998. Alcohol Clin ExpRes 2002; 26: I 553-60.http://dx.doi.org/I0. I I I I/j. I530-0277.2002. tb02455.x

47 Lefebvre LG, Ordean A, Midmer D et al. Physicians' knowledge of alcohol, tobacco and folic acid in pregnancy. Subst Abus 2007; 28:3-9. http://dx.doi.org//0.1300/J465v28n0I_02

48 Mack FR. Parental knowledge of FAS and FAE. Conference Proceedings of the Michigan Federal Chapter of the Council of Exceptional Children; 1996 Feb 29; Grand Rapids, Michigan, USA.

49 Morse BA, Idelson RJ, Sachs WH et al. Paediatricians' perspectives on Fetal Alcohol Syndrome.J Subst Abuse 1992; 4:187-95. http:// dx.doi.org/I0.1016/0899-3289(92)90018-S

50 Nanson JL, Bolaria R, Snyder RE et al. Physician awareness of Fetal Alcohol Syndrome: a survey of pediatricians and general practitioners. CMAJ 1995; I52:107|-6.

5 I Hankin JR. Fetal Alcohol Syndrome prevention research. Alcohol Res Health 2002; 26:58-65.

52 McKnight A, Merrett D. Alcohol consumption in pregnancy: a health education problem. I R Coll Gen Pract 1987; 37:73-6.

53 Paley B, O'Connor MJ, Frankel F et al. Predictors of stress in parents of children with Fetal Alcohol Spectrum Disorder. J Dev Behav Paediatr 2006; 27:396-404. http://dx.doi.org//0.1097/00004 703-200610000-00005

54 Granitsas J. Experiences of adoptive parents of children with Feta Alcohol Spectrum Disorder. Clinical Excellence for Nurse Practitioners 2004; 8:22-8.

55 Gardner J. Living with a child with Fetal Alcohol Syndrome. MCN Am J Matern Child Nurs 2000; 25:252-7. http://dx.doi. org/l0.1097/0000572 I-200009000-00007

56 Brown JD, Bednar LM, Sigvaldason N. Causes of placement breakdown for foster children affected by alcohol. Child and Adolescent Social Work Journal 2007; 24:313-32. http://dx.doi. org/I0.1007/s I0560-007-0086-9

57 Brown JD, Sigvaldason N, Bednar LM. Foster parents perception of placement needs for children with a Fetal Alcohol Spectrum Disorder. Children and Youth Services Review 2005; 27:309-27. http:// dx.doi.org/I0.1016/j.childyouth.2004.10.008

58 Gelo J, O'Malley K. Family stress in parenting a child or adolescent with FASD. Iceberg 2003; I3: I-4.

59 Sokol RJ, Janisse JJ, Louis JM et al. Extreme prematurity: an alcoholrelated birth defect. Alcohol Clin Exp Res 2007; 31:1031-7. http:// dx.doi.org/I0.I I I I/j.I530-0277.2007.00384.x

60 Volpe JJ. Cognitive deficits in premature infants. N Eng J Med I991; 325:276-8. http://dx.doi.org//0.1056/NEJMI99/07253250409

6I Czeizel AE, Petik D, Puho E. Smoking and alcohol drinking during pregnancy. The reliability of retrospective maternal self-reported information. Cent Eur J Public Health 2004; 12: $179-83$.

62 Gray R, Mukherjee RA, Rutter M. Alcohol consumption during pregnancy and its effects on neurodevelopment: what is known and what remains uncertain. Addiction 2009; 104:1270-3. http:// dx.doi.org/I0.I I I I/j. I360-0443.2008.0244I.x 
63 Hannigan JH.What research with animals is telling us about alcoholrelated neurodevelopmental disorder. Pharmacol Biochem Behav 1996; 55:489-99. http://dx.doi.org/I0.1016/S009 I-3057(96)0025 I-I

64 Sulik KK. Genesis of alcohol-induced craniofacial dysmorphism. Exp Biol Med 2005; 230:366-75.

65 Office for National Statistics. Drinking: adults' behaviour and knowledge in 2008 [Internet]. South Wales: ONS; 2009 [cited 2012 March 28]. Available from: http://www.ons.gov.uk/ons/rel/lifestyles/ drinking--adult-s-behaviour-and-knowledge/2008-report/index.html

66 Office for National Statistics. Smoking and drinking among adults, 2008 [Internet]. South Wales: ONS; 2010 [cited 2012 March 28] Available from: www.ons.gov.uk/ons/rel/ghs/general-lifestylesurvey/2009-report/smoking-and-drinking-among-adults--2009.pdf

67 Leichter J, Lee M. Method of ethanol administration as a confounding factor in studies of Fetal Alcohol Syndrome. Life Sciences 1982; 31:22I-7. http://dx.doi.org/10.1016/0024-3205(82)9058I-I

68 Cudd TA. Animal model systems for the study of alcohol teratology. Exp Biol Med (Maywood) 2005; 230:389-93.

69 Jacobson JL, Jacobson SW. Effects of prenatal alcohol exposure on child development. Alcohol Res Health 2002; 26:282-6.

70 Rasmussen C. Executive functioning and working memory in Fetal Alcohol Spectrum Disorder. Alcohol Clin Exp Res 2005; 29: I359-67. http://dx.doi.org/I0.I097/0I.alc.0000I75040.9I007.d0

7I Mattson SN, Riley EP. Parent ratings of behaviour in children with heavy prenatal alcohol exposure and IQ-matched controls. Alcohol Clin Exp Res 2000; 24:226-3I. http://dx.doi.org/I0.I I I I/j.I530-0277.2000. tb04595.x

72 Mattson SN, Goodman AM, Caine $C$ et al. Executive functioning in children with heavy prenatal alcohol exposure. Alcohol Clin Exp Res 1999; 23:1808-I5. http://dx.doi.org/I0.IIII/j.I530-0277.1999. tb04077.x

73 Burden MJ, Jacobson SW, Sokol RJ et al. Effects of prenatal alcohol exposure on attention and working memory at 7.5 years of age. Alcohol Clin Exp Res 2005; 29:443-52. http://dx.doi.org/I0.1097/0I. ALC.0000 156I25.50577.EC

74 Burden MJ, Jacobson SW, Jacobson JL. Relation of prenatal alcohol exposure to cognitive processing speed and efficiency in childhood Alcohol Clin Exp Res 2005;29: I473-83.http://dx.doi.org/ I0. I097/0 I. alc.0000I75036.34076.a0
75 Roebuck TM, Mattson SN, Riley EP. Interhemispheric transfer in children with heavy prenatal alcohol exposure. Alcohol Clin Exp Res 2002; 26:|863-7I. http://dx.doi.org/I0.1IIII/j.1530-0277.2002. tb02494.x.

76 Sampson PD, Kerr B, Carmichael Olson H et al. The effects of prenatal alcohol exposure on adolescent cognitive processing: a speed-accuracy tradeoff. Intelligence 1997; 24:329-53. http://dx.doi. org/10.1016/S0160-2896(97)90064-7

77 Spadoni AD, McGee CL, Fryer SL et al. Neuroimaging and Fetal Alcohol Spectrum Disorders. Neurosci Behav Rev 2007; 31:239-45. http://dx.doi.org/10.1016/j.neubiorev.2006.09.006

78 Mattson SN, Roesch SC, Fagerlund A et al. Towards a neurobehavioural profile of FASD. Alcohol Clin Exp Res 2010; 34:I640-50. http://dx.doi.org/I0.I I I I/j.I530-0277.20I0.0I250.x

79 Kodituwakku PW. Neurocognitive profile in children with Fetal Alcohol Spectrum Disorders. Dev Disabil Res Rev 2009; 15:218-24. http://dx.doi.org//0.1002/ddrr.73

80 Baer JS, Sampson PD, Barr HM et al. A 21 -year longitudinal analysis of the effects of prenatal alcohol exposure on young adult drinking. Arch Gen Psychiatry 2003; 60:377-85. http://dx.doi.org//0.100I/ archpsyc.60.4.377.

8I Streissguth AP, O'Malley K. Neuropsychiatric implications and longterm consequences of Fetal Alcohol Spectrum Disorders. Semin Clin Neuropsychiatry 2000; 5:I77-90. http://dx.doi.org//0.1053/ scnp.2000.6729

82 Spohr HL,Willms J, Steinhausen HC. Prenatal alcohol exposure and long-term developmental consequences. Lancet 1993; 341:907-910. http://dx.doi.org//0.1016/0140-6736(93)91207-3

83 Famy C, Streissguth AP, Unis AS. Mental illness in adults with Fetal Alcohol Syndrome or Fetal Alcohol Effects. Am J Psychiatry 1998; 155:552-4.

84 Barr HM, Bookstein FL, O'Malley KD et al. Binge drinking during pregnancy as a predictor of psychiatric disorders on the structured clinical interview for DSM-IV in young adult offspring. Am J Psychiatry 2006; 163:1061-5. http://dx.doi.org/l0.1/76/appi. ajp. 163.6.106I

85 Huggins JE, Grant T, O'Malley K et al. Suicide attemps among adults with Fetal Alcohol Spectrum Disorders: clinical considerations. Mental Health Aspects of Developmental Disabilities 2008; I I:33-40. 